EUVRES PHILOSOPHIQUES C O M P L È T E S 



\section{FRIEDRICH NIETZSGHE}

CUVRES PHILOSOPHIQUES COMPLETES

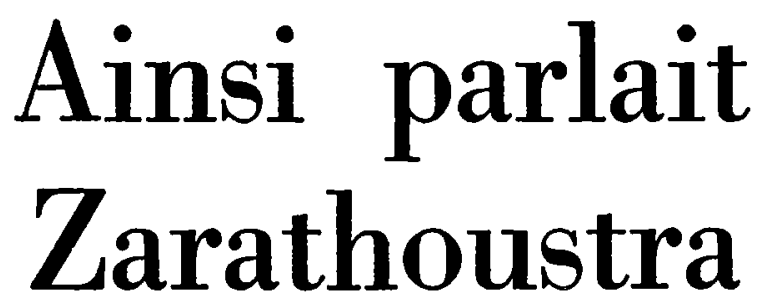

Un livre qui est pour tous et qui n'est pour personne

TEXTES ET VARIANTES

ÉTABLIS PAR

GIORGIO COLLI ET MAZZINO MONTINARI

TRADUIT DE L'ALLEMAND

PAR MAURICE DE GANDILLAC

\section{nrf}

GA L L I M A R D 
Titre original :

ALSO SPRACH ZARATHUSTRA

Edition critique des Euvres complètes de Friedrich Nietzsche établie d'après les manuscrits originaux de l'auteur et comprenant une part de texles inédits.

Éditions Gallimard, Paris, pour la langue française. Walter de Gruyter \& Co., Berlin, pour la langue allemande. Adelphi Edizioni, Milano, pour la langue italienne. Hakusuisha Publishing Company, Tokyo, pour la langue japonaise.

(C) Walter de Gruyter \& Co., 1968, pour la langue allemande. (C) Adelphi Edizioni, 1968, pour la traduction ilalienne. (C) Editions Gallimard, 1971, pour la traduclion française. 
Le texte des variantes a pu être établi grâce d l'obligeance de M. Helmut Hollzhauer, direcleur des Nationale Forschungs- und Gedenkstälten der klassischen deutschen Literatur, de M. KarlHeinz Hahn, direcleur des Archives Goethe-Schiller de Weimar, et avec l'aide de $M^{m e}$ Anneliese Clauss, des Archives GoetheSchiller.

L'édilion française est placée sous la responsabililé de Gilles Deleuze et Maurice de Gandillac. 
